\title{
Antibacterial activity of native California medicinal plant extracts isolated from Rhamnus californica and Umbellularia californica
}

Maria G Carranza*, Mary B Sevigny, Debashree Banerjee and Lacie Fox-Cubley

\begin{abstract}
Background: Antimicrobial resistance (AMR) is a major threat to global public health. Medicinal plants have long been used as remedies for infectious diseases by native cultures around the world and have the potential for providing effective treatments for antibiotic-resistant infections. Rhamnus californica (Rhamnaceae) and Umbellularia californica (Lauraceae) are two indigenous California plant species historically used by Native Americans to treat skin, respiratory and gastrointestinal infections. This study aimed to assess the in vitro antimicrobial activity of methanolic extracts of leaves and bark of $R$. and U. californica against methicillin-resistant Staphylococcus aureus (MRSA) and other Gram-positive and Gram-negative bacteria.

Methods: Methanolic extracts of leaves and bark of $R$. and U. californica were prepared by soxhlet extraction and evaluated for their antimicrobial activity against Bacillus cereus, Streptococcus pyogenes, Mycobacterium smegmatis, Staphylococcus aureus, MRSA, Escherichia coli and Pseudomonas aeruginosa using disc diffusion and minimal inhibitory concentration (MIC) assays. Chemical profiling of the extracts was performed using standard methods.
\end{abstract}

Results: All extracts inhibited the growth of MRSA and other Gram-positive bacteria with MICs of 3.3-6.0 mg/ml. Gram-negative organisms were unaffected by these extracts. U. californica extracts (leaves and bark) had the lowest MIC values. Chemical profiling detected the presence of quinones, alkaloids, flavonoids, cardenolides, tannins and saponins in these extracts. Our study is the first to report the antimicrobial properties of $R$. and $U$. californica and illustrates their promising anti-MRSA potential.

Conclusions: Our results give scientific credence to the traditional medicinal uses of these plants by the indigenous peoples of California. Further investigation of the secondary metabolites responsible for the antimicrobial activity of these extracts against MRSA is warranted.

Keywords: Methicillin-resistant S. aureus, Medicinal plants, Antimicrobial activity, Rhamnus californica, Umbellularia californica

\section{Background}

The incidence of infections by antibiotic-resistant bacteria has increased significantly over the last decade. In the U.S., over 90,000 infections per year are caused by methicillin-resistant Staphylococcus aureus (MRSA) alone [1]. Antimicrobial resistance (AMR) has also been found in strains of Streptococcus pneumonia, Escherichia coli, Pseudomonas aeruginosa, and Mycobacterium tuberculosis, to name a few. The emergence of AMR has

\footnotetext{
*Correspondence: maria.carranza@dominican.edu

Department of Natural Sciences and Mathematics, Dominican University of California, 50 Acacia Avenue, San Rafael, CA 94901, USA
}

prompted the Centers for Disease Control (CDC) and the World Health Organization (WHO) to spearhead efforts aimed at combating this dilemma through public education about the misuse of antibiotics, increased surveillance, and research focused on developing new, more effective therapies [2]. For thousands of years native peoples across the globe have used traditional medicine to treat many human diseases, including infectious diseases [3]. Native Americans produced traditional medicines from approximately 2700 species of vascular plants [4]. The medicinal ethnobotanical knowledge of Native Americans has been an important source for the identification of bioactive 
plants, and studies show a high degree of correlation between traditional medicinal uses and observed biological activity [5].

Rhamnus californica (Rhamnaceae) and Umbellularia californica (Lauraceae) are two indigenous California plant species historically used by Native Americans for their medicinal properties $[6,7]$. Specifically, R. californica was used as a decoction of leaves for the treatment of poison oak dermatitis (Costanoan tribe); crushed leaves and berries were used to heal infected sores, burns and wounds (Kawaiisu tribe); and a decoction of bark was used to treat grippe (Mendocino and Yokia tribes) [4, 8]. Similarly, $U$. californica was used as a decoction of leaves and as a steam bath for the treatment of cold symptoms (Karok, Pomo and Kashaya tribes); a poultice of leaves was applied to sores (Karok, Pomo and Kashaya tribes) and used as a treatment for poison oak dermatitis (Costanoan tribe) [9]; a decoction of leaves was used for sore throat and chest congestion (Pomo, Kashaya tribes); crushed leaves were used for nasal decongestion (Yuki tribe); and a decoction of whole plant was taken for stomachaches (Mendocino tribe) $[4,8]$. Earlier chemical studies reported the presence of anthraquinones $[10,11]$ in the genus Rhamnus, while terpenoids [9, 12], alkaloids [13], and flavonoids [14] are reported as major constituents of $U$. californica [15] with cyanogens, sugars and tannins as minor constituents [12]. Selected examples of reported structural classes from $R$. and $U$. californica are shown in Fig. 1.

The use of both species in Native American traditional medicine for the treatment of symptoms associated with skin, respiratory and gastrointestinal infections provided a rationale for investigating the in vitro antimicrobial potential of the methanolic extracts of leaves and bark of Rhamnus californica (Coffeeberry) and Umbellularia californica (California bay or California laurel) against MRSA and other types of Gram-positive and Gram-negative bacteria. We are the first to report the antibacterial activity of extracts from these two species and illustrate their promising anti-MRSA potential.

\section{Methods}

Plant material and extraction

Rhamnus californica and Umbellularia californica were obtained from the University of California at Berkeley Botanical Garden (UCBBG). Specimens were authenticated by Dr. Holly Forbes, curator of the UCBBG. Voucher specimens for each species (50.1622 and 71.0162) have been deposited at the UC Berkeley Herbarium. Leaves and bark were separated and oven dried after which they were grinded into fine powder or shavings. Thimbles were

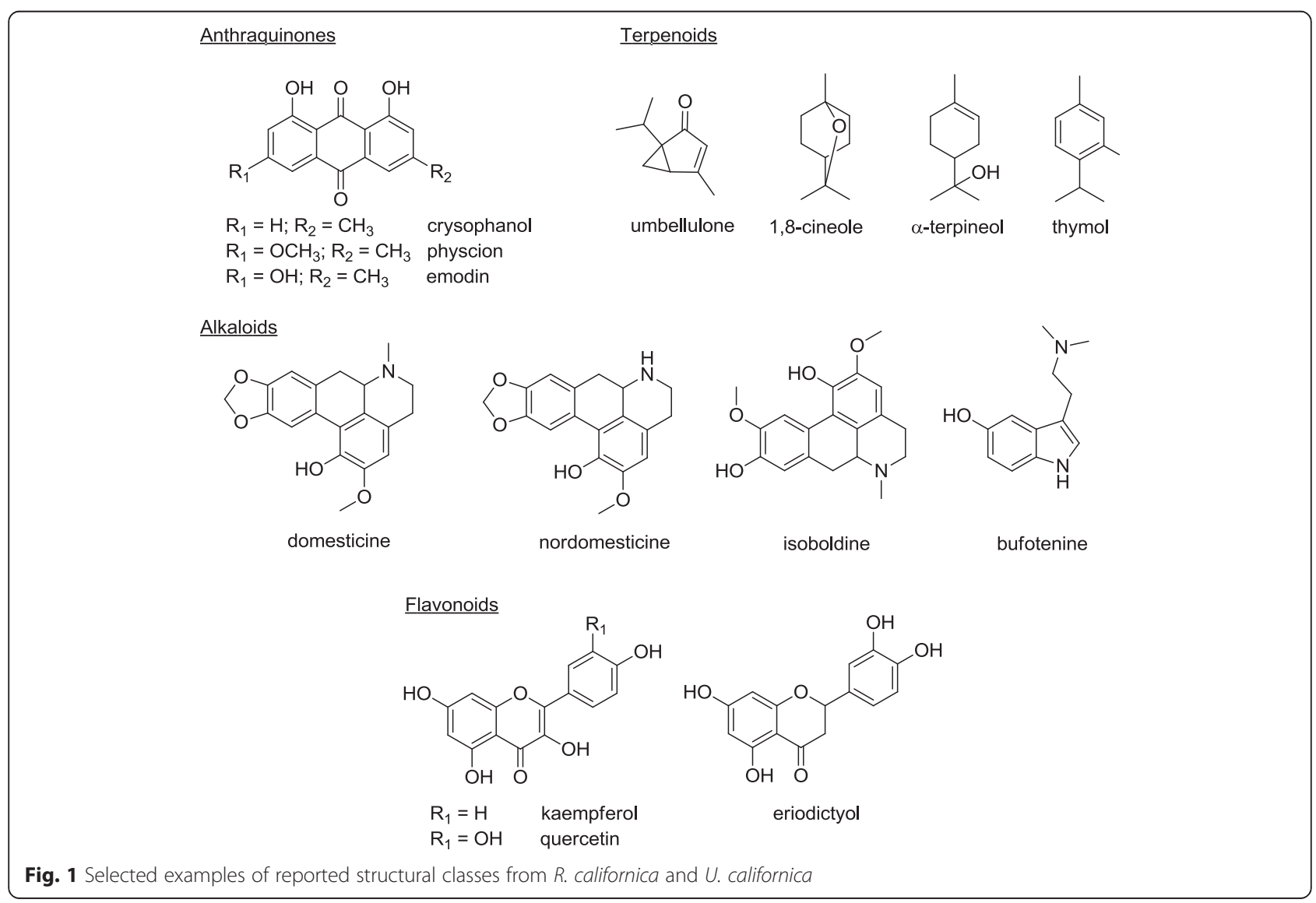


filled with dried leaf or bark material (30 g) and extracted using a Soxhlet apparatus. The plant materials were successively extracted with hexanes, dichloromethane, and methanol $(2 \times 100 \mathrm{ml}$ for $24 \mathrm{~h}$ each $)$. The resulting extracts were filtered, concentrated under reduced pressure, and kept at $4{ }^{\circ} \mathrm{C}$.

\section{Microorganisms tested}

All bacterial organisms were purchased from the American Type Culture Collection (ATCC; Manassas, VA, USA). Specific strains used were: Bacillus cereus ATCC $^{\circ} 14579^{\text {mat }}$, Escherichia coli $\mathrm{ATCC}^{\bullet} 25922^{\mathrm{m}}$, Mycobacterium smegmatis ATCC $^{\circ} 10143^{\mathrm{mi}}$, Pseudomonas aeruginosa ATCC $^{\circ} 10145^{\mathrm{mix}}$, Staphylococcus aureus ATCC $25923^{\text {max }}$, methicillin-resistant Staphylococcus aureus (MRSA) ATCC ${ }^{\ominus}$ BAA-1683 ${ }^{\text {Tw }}$, and Streptococcus pyogenes $\mathrm{ATCC}^{\circ} 10782^{\mathrm{mm}}$.

\section{Disc-diffusion assay}

The disc diffusion method developed by Kirby and Bauer was used with some modifications [16]. Initially, bacterial cultures were streaked onto tryptic soy agar plates and incubated overnight at $37{ }^{\circ} \mathrm{C}$ to obtain individual colonies. Colonies were then selected and resuspended in tryptic soy broth to achieve turbidity equal to that of a $0.5 \mathrm{McFar}-$ land Turbidity standard (BD Biosciences, Franklin Lakes, NJ, USA). Using a cotton swab, the bacterial suspension was used to inoculate a Mueller-Hinton agar plate (Carolina Biological Supply Company, Burlington, NC, USA). Various doses of plant extracts (all dissolved in methanol) were applied to $6 \mathrm{~mm}$ diameter paper discs (BD Biosciences), and the discs were then carefully placed onto the surface of the Mueller-Hinton agar plate. Plates were incubated at $35{ }^{\circ} \mathrm{C}$ for $20-22 \mathrm{~h}$, after which the diameters of the zones of inhibition around each disc were measured. Streptomycin discs (10 $\mu \mathrm{g} ; \mathrm{BD}$ Biosciences) were used as a positive control.

\section{Minimal Inhibitory Concentration (MIC) assay}

The microplate method developed by J.N. Eloff was used, with some modifications, to test the MIC of each extract for each bacterial species that demonstrated susceptibility in the Kirby-Bauer assay [17]. Briefly, bacterial colonies growing on either tryptic soy or brain heart infusion (BHI) agar plates were selected and resuspended in Mueller-Hinton broth (Carolina Biological Supply Company) to achieve turbidity equal to that of a 0.5 McFarland Turbidity standard. In a 96-well plate, $50 \mu \mathrm{l}$ aliquots of this bacterial suspension were mixed with various concentrations of each extract (or methanol, as a negative control) for a final volume of $100 \mu \mathrm{l}$ per well. The plate was incubated at $35{ }^{\circ} \mathrm{C}$ for $20-22 \mathrm{~h}$. Due to the slow growth of $M$. smegmatis, that particular assay plate was incubated for 46-48 h. In order to better visualize bacterial growth, $40 \mu \mathrm{l}$ of $0.2 \mathrm{mg} / \mathrm{ml} p$-iodonitrotetrazolium violet (INT;
Sigma-Aldrich Corp., St. Louis, MO, USA) were then added to each well, and the plate was incubated at $37{ }^{\circ} \mathrm{C}$ for another $30 \mathrm{~min}$. Wells were analyzed visually for the development of a reddish hue, which would indicate bacterial growth.

\section{Chemical profiling}

Qualitative detection of alkaloids, flavonoids, leucoantocyanidins, cardenolides, tannins, saponins, steroids and quinones was performed using standard procedures [18-21]. Each assay was performed in triplicate.

\section{Results}

\section{Antimicrobial activity}

The antimicrobial activity of the three methanolic extracts was initially assessed using the Kirby-Bauer disc diffusion assay. Extract doses ranging from 1 to $25 \mathrm{mg}$ were tested on the Gram-negative organisms $E$. coli and $P$. aeruginosa and on the Gram-positive bacteria B. cereus, $S$. pyogenes, S. aureus, and MRSA. Streptomycin $(10 \mu \mathrm{g} / \mathrm{disc})$ was used as a positive control, and $100 \%$ methanol, the extract solvent, was used as negative control. The Gramnegative bacteria were virtually unaffected by the extracts. However, all of the Gram-positive bacteria demonstrated sensitivity to each extract at doses between 1 and $5 \mathrm{mg}$ (Table 1). Of the three extracts, the one from $R$. californica leaves appeared to be the most active. Interestingly, its greatest effect was seen on the only antibiotic-resistant strain tested- MRSA.

\section{Minimal Inhibitory Concentration (MIC)}

After having determined that all the extracts significantly inhibited the growth of MRSA and other Gram-positive organisms, minimal inhibitory concentration (MIC) assays were performed (Table 2). Due to difficulty culturing $S$. pyogenes within the 96-well plate, the MIC assay could not be carried out on this organism. For the remaining four organisms, MIC values ranged between 3.3 and $6.0 \mathrm{mg} /$ $\mathrm{ml}$. B. cereus exhibited the greatest sensitivity to the three extracts, and MRSA predictably required slightly higher concentrations to inhibit growth. Although difficulty in growing a lawn of M. smegmatis prevented it from being tested using the Kirby-Bauer assay, the MIC assays demonstrated that even this acid-fast organism was susceptible to the extracts. Additionally, according to these MIC data, the $U$. californica extracts, rather than the $R$. californica extract, appeared to be most active.

\section{Chemical profiling}

Alkaloids, flavonoids, cardenolides and saponins were detected in the methanolic extracts of $R$. californica leaves and $U$. californica leaves and bark. Leucoanthocyanidins were detected in both $U$. californica leaves and bark but not in R. californica leaves. Tannins were detected in the 
Table 1 Antimicrobial activity of methanolic extracts of R. californica and U. californica analyzed by Kirby-Bauer disc-diffusion assay

\begin{tabular}{|c|c|c|c|c|c|c|c|}
\hline & & & & terial Strains & & & \\
\hline & & & Diameter o & one of Inhibition (mm) & & & \\
\hline Plants & Dose (mg) & $\begin{array}{l}\text { B. cereus ATCC } \\
14579\end{array}$ & $\begin{array}{l}\text { E. coli ATCC }{ }^{\oplus} \\
25922\end{array}$ & $\begin{array}{l}\text { P. aeruginosa ATCC } \\
10145\end{array}$ & $\begin{array}{l}\text { S. aureus ATCC } \\
25923\end{array}$ & $\begin{array}{l}\text { MRSA } A^{1} \text { ATCC }^{\oplus} \\
\text { BAA-1683 }\end{array}$ & $\begin{array}{l}\text { S. pyogenes } \\
\text { ATCC }^{\circledR} 10782\end{array}$ \\
\hline R. californica & & & & & & & \\
\hline Leaves & 1 & $10.0 \pm 2.1$ & -- & -- & -- & 10.0 & 9.0 \\
\hline & 5 & $12.3 \pm 0.5$ & -- & -- & $11.0 \pm 1.2^{* *}$ & 15.0 & 12.0 \\
\hline & 10 & $13.0 \pm 0.0$ & -- & -- & $12.5 \pm 2.1^{\psi}$ & 16.0 & 14.0 \\
\hline & 25 & $14.3 \pm 0.5$ & -- & -- & $14.0 \pm 1.4^{* *}$ & n.t. & n.t. \\
\hline U. californica & & & & & & & \\
\hline Leaves & 1 & $9.0 \pm 0.0$ & -- & -- & -- & 8.0 & 8.0 \\
\hline & 5 & $9.5 \pm 0.5$ & -- & -- & $9.3 \pm 1.0^{* *}$ & 9.0 & 11.0 \\
\hline & 10 & $9.3 \pm 0.5$ & -- & -- & $10.5 \pm 1.4^{\psi}$ & 10.0 & 15.0 \\
\hline & 25 & $10.0 \pm 0.0$ & -- & -- & $10.9 \pm 2.0^{* *}$ & n.t. & n.t. \\
\hline Bark & 1 & -- & -- & -- & $8.0 \pm 0.0^{\psi}$ & -- & -- \\
\hline & 5 & $9.3 \pm 0.5$ & -- & -- & $12.8 \pm 2.6^{* *}$ & 9.0 & 8.0 \\
\hline & 10 & $10.3 \pm 0.5$ & -- & -- & $17.5 \pm 1.4^{\psi}$ & 10.0 & 11.0 \\
\hline & 25 & $11.7 \pm 0.5$ & -- & -- & $16.0 \pm 1.2^{* *}$ & n.t. & n.t. \\
\hline Streptomycin & 0.01 & $23.8 \pm 1.2$ & $19.8 \pm 0.2$ & $10.4 \pm 0.3$ & $18.9 \pm 1.0$ & $17.0 \pm 0.0$ & $18.0 \pm 0.0$ \\
\hline Methanol & $100 \%$ & -- & -- & -- & -- & -- & -- \\
\hline
\end{tabular}

Data represented as averages \pm SD. --, no significant zone of inhibition; n.t., not tested; ${ }^{1}, n=1 ; \Psi, n=2 ;{ }^{* *}, n=4$; remaining data (B. cereus, E. coli, and $P$. aeruginosa) represent sample size of $3(n=3)$

leaves of both $R$. and $U$. californica but not in the bark of $U$. californica. Steroids were only detected in the bark of $U$. californica but not in the leaves of $U$. or $R$. californica. Finally, quinones were detected only in the leaves of $R$. Californica (Table 3).

\section{Discussion}

Despite the alarming rise in AMR over the last several years, resistance to antimicrobial drugs is nothing new. In 1945- two years after the mass-production of penicillin- over $20 \%$ of $S$. aureus strains isolated from hospitalized patients were penicillin-resistant [22]. Subsequent antibiotics such as streptomycin, tetracycline, methicillin, cephalothin, gentamicin, cefotaxime, and linezolid all followed suit, resulting in the emergence of resistant bacterial strains one to four years after their introduction [22]. History indicates that for every new antimicrobial drug developed, a proportion of bacteria will become resistant to it and pose a greater threat to public health.
Therefore, alternative strategies must be considered if antimicrobial resistance is to be successfully combated. One alternative is the use of medicinal plants, which for many cultures continue to play a crucial role in the primary care of patients [3]. In fact, the World Health Organization supports combining western with traditional medicinal practices in order to develop truly effective remedies for our modern health challenges [23].

It is widely accepted that the antimicrobial activities and physiological effects from plant therapies are due to the biosynthesis of secondary metabolites produced by plants as a defense mechanism [24]. Very limited chemical profiling work has been done on $R$. californica (as mentioned previously, earlier chemical studies reported the presence of anthraquinones [10, 11] in the genus Rhamnus), while terpenoids [9, 12], alkaloids [13], and flavonoids [14] are reported as major constituents of $U$. californica [15] with cyanogens, sugars and tannins as minor constituents [12]. Our study is the first to detect the

Table 2 Minimum inhibitory concentration (MIC) of methanolic extracts of R. californica and U. californica (mg/ml)

\begin{tabular}{|c|c|c|c|c|}
\hline Plants & B. cereus ATCC ${ }^{\circledR} 14579$ & S. aureus ATCC ${ }^{\circledR} 25923$ & MRSA ATCC ${ }^{\circledR}$ BAA-1683 & M. smegmatis ATCC ${ }^{\circledR} 10143$ \\
\hline R. californica Leaves & $4.0 \pm 0$ & $6.0 \pm 0^{*}$ & $6.0 \pm 0^{*}$ & $5.0 \pm 1.4^{*}$ \\
\hline U. californica Leaves & $4.0 \pm 0$ & $4.3 \pm 0.5$ & $5.5 \pm 1.0^{*}$ & $4.7 \pm 1.2$ \\
\hline U. californica Bark & $3.3 \pm 1.2$ & $4.0 \pm 0$ & $5.0 \pm 1.4^{*}$ & $6.0 \pm 2.1$ \\
\hline Methanol & -- & -- & -- & -- \\
\hline
\end{tabular}

Values represent averages \pm SD. - , not active; most experiments were repeated three times $(n=3) ;{ }^{*} n=2$ 
Table 3 Extract yield and chemical profile of methanolic extracts of $R$. californica and $U$. californica

\begin{tabular}{llll} 
& & Plants & \\
& L. californica & U. californica & \\
& Leaves & Leaves & Bark \\
\hline Extract Yield (\% w/w) & 13.9 & 28.9 & 5.75 \\
Alkaloids & + & + & + \\
Flavonoids & + & + & + \\
Leucoanthocyanidins & - & + & + \\
Cardenolides & + & + & + \\
Tannins & + & + & + \\
Saponins & + & + & + \\
Steroids & - & - & - \\
Quinones & + & - & +
\end{tabular}

+, present; -, absent

presence of quinones, alkaloids, flavonoids, cardenolides, tannins and saponins in $R$. californica (leaves). In addition, alkaloids, flavonoids, cardenolides, saponins, tannins (leaves), and steroids (bark) were detected in $U$. californica. Individually, each of these classes of compounds varies considerably in antimicrobial capacity [25]. At the same time, some of the structural classes found in $R$. and $U$. californica have recently shown promising anti-MRSA potential. Specifically, a structural analog of the anthraquinone emodin, found in the genus Rhamnus, and a novel class of synthetic antibacterial cationic anthraquinones have shown potent antibacterial effects against MRSA [26, 27]. Likewise, structural analogs of flavonoids kaempferol, quercetin and eriodictyol [28], found in $U$. californica, and plant extracts containing terpenoids umbellulone, 1,8-cineole, $\alpha$-terpineol and thymol among others [29-31] have shown anti-MRSA activity. Interestingly, even though 1,8-cineole exhibits little inherent antimicrobial activity, it has been shown to enhance the potency of other antimicrobials against MRSA [31]. Therefore, it is likely that the antimicrobial activity observed herein is due to the synergistic effects of all or most of the secondary metabolites present in each extract $[31,32]$. In addition, the many compounds in the extracts may affect the bacteria via several different mechanisms, thus decreasing the likelihood of selecting for a resistant strain.

Our study is the first to report the antimicrobial potential of the methanolic extracts of leaves and bark of $R$. californica and $U$. californica, all of which significantly inhibited growth of Gram-positive bacteria such as B. cereus, S. pyogenes, and $S$. aureus, as well as the acid-fast organism $M$. smegmatis. Most intriguing was the discovery that these plant extracts were effective at controlling the growth of MRSA, one of the most ominous AMR strains, with MICs of $3.3-6.0 \mathrm{mg} / \mathrm{ml}$. While we acknowledge that these MIC values are relatively high (in comparison to the generally accepted notion that plant extracts have significant antimicrobial activity if their MIC values are $100 \mu \mathrm{g} / \mathrm{ml}$ or lower), the fact that the two Gram-negative organisms $E$. coli and $P$. aeruginosa were virtually unaffected by these extracts is noteworthy and indicates that the antimicrobial effects on the Gram-positive organisms are specific and thus significant. This complete lack of activity on the Gram-negative organisms is most likely due to the protective nature of the outer membrane of their cell walls. Furthermore, MIC values similar to those obtained in this study have been reported recently by other researchers, such as: Farooqui et al., who tested the antibacterial activity of $C$. Sinensis and J. Regia against multidrug-resistant bacteria including MRSA [33]; Siwe Noundou et al., who demonstrated the antibacterial activity of A. floribunda against B. cereus and S. aureus [34]; and Zuo et al., who tested the antibacterial activity of 19 Chinese medicinal plants against MRSA [35]. Interestingly, the study by Zuo et al. showed that the MIC value of the isolated active component was 20-times greater than that of the crude extract [35].

Due to the limited amount of starting material available it was not possible to test the antimicrobial activity of our plant extracts on an extensive number of microorganisms. However, we successfully assessed the in vitro antimicrobial activity of these plant extracts against a MRSA strain

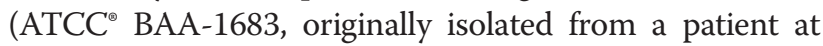
the Henry Ford Hospital in 2004) and a variety of Grampositive and Gram-negative bacteria. Further investigation of the antimicrobial activity of these extracts against other clinical isolates of MRSA is warranted.

\section{Conclusion}

Our results demonstrate the antimicrobial properties of $R$. and $U$. californica and illustrate their promising antiMRSA potential. The findings reported herein give scientific credence to the traditional medicinal uses of these plants by the indigenous peoples of California and suggest that extracts of $R$. and $U$. californica merit further chemical study as natural antibiotics to identify the secondary metabolite(s) responsible for their antimicrobial activity, since such structures could serve as valuable therapeutic anti-MRSA leads.

\section{Competing interests}

The authors declare that they have no competing interests.

\section{Authors' contributions}

MGC conceived of the study, participated in the plant collection and carried out the extraction and chemical profiling of extracts. MBS designed the disc diffusion assay. MGC and MBS designed the MIC assay. LF carried out the disc diffusion assay. DB carried out the MIC assay and performed statistical analysis. MGC and MBS drafted the final manuscript. All authors read and approved the final manuscript. 


\section{Acknowledgements}

The authors wish to thank Dr. Holly Forbes, curator of the Berkeley Botanical Gardens, for her invaluable help collecting the plant species from their natural habitats and authenticating every specimen. Special thanks also go out to Dr. Tyler Johnson for his valuable suggestions and critical reading of this manuscript, and Chris Endicott and Steve Wood for technical support. These studies were supported financially by the Department of Natural Sciences and Mathematics at Dominican University of California.

\section{Received: 8 January 2015 Accepted: 15 May 2015}

\section{Published online: 23 May 2015}

\section{References}

1. Klevens RM, Morrison MA, Nadle J, Petit S, Gershman K, Ray S, et al. Invasive methicillin-resistant Staphylococcus aureus infections in the United States. JAMA. 2007;298(15):1763-71.

2. World Health Organization (WHO). Antimicrobial Resistance. In: Fact Sheet No 194. 2014. http://www.who.int/mediacentre/factsheets/fs194/en/. Accessed 07 Aug 2014

3. Fabricant DS, Farnsworth NR. The value of plants used in traditional medicine for drug discovery. Environ Health Perspect. 2001;109 Suppl 1:69-75.

4. Moerman DE. Native American medicinal plant : an ethnobotanical dictionary. Portland, Or: Timber Press; 2009.

5. O'Neill T, Johnson JA, Webster D, Gray CA. The Canadian medicinal plant Heracleum maximum contains antimycobacterial diynes and furanocoumarins. J Ethnopharmacol. 2013;147(1):232-7.

6. Garcia C, Adams JD. Healing with medicinal plants of the west: cultural and scientific basis for their use: La Crescenta. CA: Abedus Press; 2005.

7. Chesnut VK. Plants used by the Indians of Mendocino County, California. Washington D.C: U.S: National Herbarium; 1974.

8. Moerman DE. Native American Ethnobotany. Portland, OR: Timber Press; 1998.

9. Lin L, Ying B, Sweeney M, Wang Z, Hwang Y. A monoterpene from Umbellularia californica. Phytochemistry. 1994;37(3):905-6.

10. Van den Berg AJJ, Radema MH, Labadie RP. Anthra-derivatives in suspension cell cultures of rhamnus frangula. Plant Sci. 1988;56(2):123-7.

11. Van den Berg AJJ, Radema MH, Labadie RP. Effects of light on anthraquinone production in Rhamnus purshiana suspension cultures. Phytochemistry. 1988;27(2):415-7.

12. Lawrence BM, Bromstein AC, Langenheim JH. Terpenoids in Umbellularia californica. Phytochemistry. 1974;13(9):2009.

13. Pech B, Bruneton J. Alcaloides de I'Umbellularia californica. J Nat Prod. 1984;47(2):390

14. Neville HA, Bohm BA. Flavonoids of Umbellularia californica. Phytochemistry. 1994;36(5):1229-31.

15. Tabanca N, Avonto C, Wang M, Parcher JF, Ali A, Demirci B, et al. Comparative investigation of umbellularia californica and laurus nobilis leaf essential oils and identification of constituents active against aedes aegypti. J Agric Food Chem. 2013;61(50):12283-91.

16. Bauer AW, Perry DM, Kirky WM. Single-disk antibiotic-sensitivity testing of staphylococci; an analysis of technique and results. AMA Arch Intern Med. 1959;104(2):208-16.

17. Eloff JN. A sensitive and quick microplate method to determine the minimal inhibitory concentration of plant extracts for bacteria. Planta Med. 1998;64(8):711-3.

18. Duncan AC, Jager AK, van Staden J. Screening of Zulu medicinal plants for angiotensin converting enzyme (ACE) inhibitors. J Ethnopharmacol. 1999;68(1-3):63-70.

19. Evans WC, Trease GE, Evans D. Trease and Evans' pharmacognosy. Edinburgh; New York: WB Saunders; 2002.

20. Harborne JB. Phytochemical methods: a guide to modern techniques of plant analysis. London; New York: Chapman and Hall; 1998

21. Wagner H, Bladt S, Zgainski EM. Plant drug analysis : a thin layer chromatography atlas. Berlin; New York: Springer; 1984.

22. Taubes G. The bacteria fight back. Science. 2008;321(5887):356-61.

23. World Health Organization (WHO). Traditional Medicine Strategy 2013-2014. Geneva, Switzerland: WHO Press; 2013.

24. Demain AL, Fang A. The natural functions of secondary metabolites. Adv Biochem Eng Biotechnol. 2000;69:1-39.

25. Radulovic NS, Blagojevic PD, Stojanovic-Radic ZZ, Stojanovic NM. Antimicrobial plant metabolites: structural diversity and mechanism of action. Curr Med Chem. 2013;20(7):932-52
26. Hatano T, Kusuda M, Inada K, Ogawa TO, Shiota S, Tsuchiya T, et al. Effects of tannins and related polyphenols on methicillin-resistant Staphylococcus aureus. Phytochemistry. 2005;66(17):2047-55.

27. Chan KY, Zhang J, Chang CW. Mode of action investigation for the antibacterial cationic anthraquinone analogs. Bioorg Med Chem Lett. 2011;21(21):6353-6.

28. Johari SA, Kiong LS, Mohtar M, Isa MM, Man S, Mustafa S, et al. Efflux inhibitory activity of flavonoids from Chromolaena odorata against selected methicillin-resistant Staphylococcus aureus (MRSA) isolates. Afr J Microbiol Res. 2012;6:5631-5.

29. Araújo FM, Passos M, Lima E, Roque NF, Guedes M, de Souza-Neta LC, et al. Composition and antimicrobial activity of essential oils from Poiretia bahiana C. Müller (Papilionoideae-Leguminosae). J Braz Chem Soc. 2009;20:1805-10.

30. Vijayakumar A, Duraipandiyan V, Jeyaraj B, Agastian P, Raj MK, Ignacimuthu S. Phytochemical analysis and in vitro antimicrobial activity of Illicium griffithii Hook. f. \& Thoms extracts. Asian Pac J Trop Dis. 2012;2(3):190-9.

31. Chao S, Young G, Oberg C, Nakaoka K. Inhibition of methicillin-resistant Staphylococcus aureus (MRSA) by essential oils. Flavour Fragrance J. 2008;23(6):444-9.

32. Morones-Ramirez JR, Winkler JA, Spina CS, Collins JJ. Silver enhances antibiotic activity against gram-negative bacteria. Sci Transl Med. 2013;5(190):190ra81.

33. Farooqui A, Khan A, Borghetto I, Kazmi SU, Rubino S, Paglietti B. Synergistic antimicrobial activity of camellia sinensis and juglans regia against multidrug-resistant bacteria. PLoS One. 2015;10(2):e0118431

34. Siwe Noundou X, Krause RWM, van Vuuren SF, Tantoh Ndinteh D, Olivier DK. Antibacterial activity of the roots, stems and leaves of Alchornea floribunda. J Ethnopharmacol. 2014;151(2):1023-7.

35. Zuo GY, Wang GC, Zhao YB, Xu GL, Hao XY, Han J, et al. Screening of Chinese medicinal plants for inhibition against clinical isolates of methicillinresistant Staphylococcus aureus (MRSA). J Ethnopharmacol. 2008;120(2):287-90.

\section{Submit your next manuscript to BioMed Central and take full advantage of:}

- Convenient online submission

- Thorough peer review

- No space constraints or color figure charges

- Immediate publication on acceptance

- Inclusion in PubMed, CAS, Scopus and Google Scholar

- Research which is freely available for redistribution 